Dossier: Las certezas de Jano. Reflexiones sobre América Latina en el siglo XXI (antes y después de la pandemia)

Coordinado por Laura Luciani

Anuario No 32 / ISSN 1853-8835 / 2020

http://anuariodehistoria.unr.edu.ar/ojs/index.php/Anuario/index

\title{
Las certezas de Jano. Reflexiones sobre América Latina en el siglo XXI (antes y después de la pandemia)
}

"Los augurios suelen hallarse en los principios" Ovidio, Tratado sobre Fastos

Cuando me propusieron coordinar este dossier estábamos expectantes de los procesos de movilización en Chile y Ecuador, iniciábamos las denuncias contra el golpe en Bolivia y hacía un año que conviviamos con el registro de la derecha bolsonarista en Brasil. Eran tiempos, como los actuales, en que se profundizaban los debates sobre escenarios de producción extractivista, modelo de maldesarrollo (Svampa y Viale, 2014) y formas alternativas para una economía no ecocida que reconociera a la naturaleza como portadora de derechos. Crecía la llamada "marea verde" entre plazas y calles del mundo y al ritmo de "El violador eres tú" desnudaba las lógicas patriarcales del estado y sus brazos materiales, las fuerzas represivas y la justicia. En este contexto, la convocatoria no me tomó desprevenida sino definiendo cómo pensar esta conflictividad múltiple de una América Latina jalonada entre las derechas (nuevas) en acción y las intensas movilizaciones, que desde diversas prácticas y discursos cuestionaban el modelo económico y político vigente y avanzaban con dinámicas promisorias.

Una y otra vez venía a mi mente la imagen de Jano, el dios romano que no tiene parangón en el Olimpo. La recurrencia de esa figura para representar el escenario del siglo XXI latinoamericano me provocaba desconcierto y, a la vez, me estimulaba. ¿Acaso no es una osadia resucitar una deidad en el derrumbe (o, siendo menos optimistas, entre las grietas) de los enunciados civilizatorios occidentales? Me pregunto si no se comete el mayor de los perjurios al invocar su silueta simétrica, blanca, masculina, de cuerpo perfecto para esta parte del mundo. Jano es, además, el de rostro bifronte que mira en dos direcciones siempre opuestas y esa no siempre es una metáfora legítima para reflexionar sobre América Latina (o sobre cualquier espacio cultural, identitario, humano). Su mito conjura construcciones binarias, un doble opuesto, la simetría del dos que colma y calma. En una lectura simple y poco atenta, el Jano que emerge en 
esa representación mira con rostros simétricos ascenso de derechas y movimientos sociales del siglo XXI latinoamericano. Sin embargo, la metáfora divina que me estimula reflexionar sobre América Latina se delinea en otras tramas. Es el Jano de las multiplicidades, que no posee un único horizonte donde mirar, imposibilitado de universalizar lo que observa. Que construye sobre lo efimero del presente, tiempos que unen pasados y futuros, y despliega posibilidades tras sus muchas puertas. Así, las certezas de enero de 2020, son las de un dios veraniego que centrifuga y expulsa ciclos abiertos y en movimiento. Sin saberlo entonces, son las certezas de Jano en un mundo sin pandemias.

Para reflexionar sobre las problemáticas sociales, políticas y económicas que se despliegan en el siglo XXI en esta parte (geográfica, cultural, simbólica) del mundo es necesario historizar en el mediano y corto plazo. En el tiempo medio convergieron de forma articulada al menos tres procesos. El primero, fue el desarrollo y consolidación de proyectos neoliberales que modificaron las dinámicas de acumulación capitalistas $\mathrm{y}$ sin ser un proceso unilineal ni progresivo se instalaron en la región con ritmos desiguales en el último cuarto del siglo XX. En segundo lugar, y en paralelo al proceso mencionado, se definieron nuevos escenarios gubernamentales entre dictaduras cruentas y democracias que se establecieron con diversos grados de estabilidad y sostén social que, finalizado el siglo $\mathrm{XX}$, parecian asumir condiciones de irreversibilidad. Por último, se produjeron ciclos de flujo y reflujo en la emergencia de movimientos sociales, tramados en las condiciones expuestas anteriormente, entre la decadencia de los sistemas tradicionales de participación política y la crisis profunda de las izquierdas tras la caída del socialismo real. Estos incorporaron nuevas modalidades de acción y definición, sostenidas desde lo particular, y enlazadas por un discurso común contra el neoliberalismo (Modonessi, 2019) y contra el universalismo capitalista. Así, las formas organizativas y las movilizaciones asentadas en nuevas identidades (que habian sido excluidas) politicas emergieron como horizontes temporales que atravesaron los designios del fin de la historia y recompusieron las tramas de las resistencias.

Las primeras dos décadas del XXI, incorporaron una temporalidad de corto plazo que se yuxtapone a la anterior. En estos años, se evidenció la profundidad de las crisis económica, social y política, producto de la consolidación de políticas neoliberales y de un régimen de acumulación que agudizó las desigualdades sociales en Latinoamérica y las asimetrías relacionales con el resto del mundo. Consecuencia de, o como resistencia a ese proceso, en el cruce de los dos siglos se activó la intensa convulsión social que, con expresiones diversas, cuestionó el sistema vigente. La instalación de experiencias políticas nuevas en el segundo lustro de la década del 2000 prometía abrir un escenario decisivo para el cambio de rumbo. Al calor de los acontecimientos, algunxs 
autores caracterizaron a estos gobiernos como progresistas (Borón, 2012, García Linera, 2017) y los identificaron como potenciales salidas del modelo neoliberal y rearticuladores de la conflictividad emergente. Para otrxs, esos proyectos eran meras vallas de contención o estabilizadores de los procesos sociales en marcha (Machado y Zibecchi, 2016). Lo cierto es que, en tanto apuesta a una alternativa política, las experiencias de inicios de siglo fueron desplazadas con golpes o estrategias electorales que permitieron el rápido avance de las nuevas derechas latinoamericanas. Cómo leer esas experiencias y los contextos de reversión de los últimos años representa un desafio que requiere una mirada múltiple, que no se detiene exclusivamente en el cambio de signo político, sino que recupera y articula variables más longevas de desarrollo y acumulación capitalista, de modificaciones en la estructura del estado como así también de las modalidades que asumieron las prácticas contestatarias, que se transformaron radicalmente en estas dos décadas de vaivenes politicos.

A este escenario tan complejo, hoy se agrega una condición que imponen los nuevos contextos generados por epidemias globales - que en estos meses trajeron incertidumbres y diagnósticos sociales más vulnerables a la equivocación-. La clara desigualdad de usos y desarrollo tecnológico en los países latinoamericanos es una condición que avanza con una aceleración nunca antes imaginada, ni siquiera en los años noventa cuando emergieron las primeras lecturas sobre la revolución tecnológica. Este escenario nos obliga a repensar cómo se reproducen y se cualifican las diferencias regionales y las desigualdades sociales en los países latinoamericanos.

En esa línea, el dossier que presentamos asume una lectura que recupera el mediano y corto plazo para pensar algunos procesos actuales gravitantes desde perspectivas y estrategias teórico metodológicas diversas. Como Jano y su rostro bifronte que mira hacia atrás desde un presente revitalizado y, al mismo tiempo, asume la imposibilidad de lecturas unívocas, los trabajos que se presentan a continuación reflexionan sobre los fenómenos sociales y políticos que son parte de la agenda actual.

El artículo de Alejandro Schneider inaugura el dossier y recupera algunos rasgos del gobierno de Evo Morales para complejizar la explicación del golpe que lo derrocó en el año 2019. Su análisis se inscribe en una línea temporal que parte de los profundos cambios que vivió Bolivia entre las décadas del 80 y 90 del siglo XX para comprender las diversas instancias organizativas y ciclos de movilización, así como las alianzas múltiples que llevaron a Morales a la presidencia y se modificaron en las sucesivas gestiones del MAS. El autor destaca aspectos que considera centrales en la metamorfosis de esa relación. En especial, la incapacidad para resolver las tensiones entre los proyectos de

\section{anuario.}


las diversas fuerzas que acompañaron inicialmente a Morales. Además, sostiene que fueron las políticas desplegadas entre mediados de la segunda presidencia y 2019 las que generaron diversos horizontes conflictivos entre el gobierno y sectores de la Central Obrera Boliviana (COB), así como con diversas organizaciones indigenas. Por eso, cuando se produjo el derrocamiento de Evo Morales, su presidencia se encontraba en un momento de fuerte debilidad y conflictividad interna. En esta línea, la provocadora propuesta del autor abre una lectura más intensa que recuperamos: no fue solo un golpe encabezado por las Fuerzas Armadas y acompañado por una elite de derecha local con la venia del gobierno norteamericano, sino que se produjo entre consensos activos, aunque efimeros. Así, la perspectiva histórica que inaugura Schneider en este trabajo permite complejizar el análisis respecto de los avances de la derecha en el siglo XXI, un desafio que además debe leerse ahora a la luz de los nuevos acontecimientos, las elecciones de octubre de este año.

En el segundo artículo, Daniel Aarão Reis analiza la extrema derecha en Brasil y su triunfo electoral. Propone reponer la densidad politica de ese proceso en clave histórica, tramado en un contexto internacional de ascenso de las derechas en el que se inscribe la experiencia singular del bolsonarismo en Brasil. En esta dirección, caracteriza en términos económicos y políticos la coyuntura de finales del siglo XX y principios del siglo actual, y plantea que fue un ámbito favorable para el ascenso de las derechas, a través de la apropiación e instrumentalización del sistema democrático $\mathrm{El}$ autor sostiene que las condiciones que habilitaron la llegada de Bolsonaro al gobierno devienen de un profundo desgaste del sistema politico, producido entre 1988 y 2018, que se articuló con tradiciones autoritarias propias de la sociedad y la política brasilera. Asimismo, repone una lectura de los últimos años del gobierno del PT y las acciones de la derecha que permitieron el incremento de popularidad y legitimidad del propio Bolsonaro. Para Aarão Reis, la victoria del presidente actual se equilibra entre esas tres tendencias que manifiestan la continuidad del autoritarismo en Brasil, aunque resignificado a través de estrategias novedosas que surgieron en el siglo XXI. Por último, propone avanzar en una agenda común de partidos y movimientos de izquerdas contra las derechas en su país.

En los dos artículos mencionados, el eje de análisis remite al marco de acción y los escenarios que habilitan el camino a nuevas derechas. No obstante, los que continúan dimensionan problemáticas asociadas a diversos colectivos sociales contestatarios que en el siglo XXI adquirieron preponderancia en la región. En particular, cada trabajo pone el foco en uno de los tantos movimientos sociales que permean y trasvasan la capilaridad social actual. Luna Follegatti y Pierina Ferreti recuperan el movimiento feminista contemporáneo y lo inscriben en continuidad con las diversas oleadas de feminismos en la región. En esta dirección, señalan que una de las características centrales es la potencia de 
movilización y visibilidad trasnacional que se define en torno a lemas $\mathrm{e}$ intervenciones culturales. Para las autoras, la denuncia contra la violencia de hacia las mujeres y cuerpos feminizados es una de las demandas que permite transversalizar el movimiento y asumir dinámicas que las alejan de las tipologías clásicas de movimientos sociales. Otro aspecto que cobra relevancia es el debate en torno a la reproducción social que, retomando conceptualizaciones que tienen casi cincuenta años, actualiza la discusión en las tramas de las sociedades neoliberales. Si bien este debate se asume desde lo teórico, evidencia los modos en que el feminismo articula sus reflexiones con otras dimensiones de la esfera social, económica y politica que, según las autoras se vislumbra como clave sustantiva de las proyecciones venideras del movimiento feminista.

El trabajo de Gisela Hadad aborda el desarrollo de la megaminería y sus resistencias en Argentina. Analiza la instalación de las grandes empresas mineras y sus proyectos en algunas regiones y compara su impacto económico político y social en términos regionales y nacionales. Centra su atención en la continuidad tanto de políticas nacionales y provinciales como en el avance de las empresas megamineras luego de las modificaciones en las leyes producidas hacia finales de los años noventa. En este sentido, sostiene que el avance y consolidación del extractivismo no se vio modificado por los cambios de gobierno. Además, la autora propone incorporar a este análisis el incipiente desarrollo de la extracción de litio que, si bien no utiliza los mismos métodos de explotación, comparte con las megamineras a cielo abierto las mismas dinámicas de territorialización empresarial. Por último, reconstruye algunas experiencias de resistencia a la implantación de los emprendimientos mineros en algunas regiones y señala la incidencia de la acumulación de experiencias de luchas. Para Hadad, la organización de espacios de resistencia fue fundamental para limitar este tipo de explotaciones.

Cierra el dossier, el artículo de Fernando Pairican y Eduardo López Bravo que ofrece una lectura de las problemáticas de los movimientos mapuche en Chile actual. Su análisis pone énfasis en la larga duración y recupera la matriz constitutiva del proceso de explotación de la llamada Araucanía y los pueblos mapuche. En este sentido, los autores exponen los modos violentos en que la región fue "integrada" así como los procesos económicos sociales que se desplegaron en el siglo XX. No obstante, enfatizan en aspectos de mediano plazo, fundamentalmente en el proyecto político y económico desplegado por la dictadura pinochetista en la región, lo que aporta a la explicación de las nuevas lógicas de despojo y exclusión a las comunidades mapuche. Pairican y López sostienen que esta es una variable clave para explicar los procesos de levantamiento en las últimas décadas. Así, este trabajo nos convoca a 
reflexionar sobre cuáles han sido los factores para comprender la tensa relación entre estado nacional y movimientos mapuche, pero también nos invita a insertar esta problemática en el nuevo contexto abierto en 2019, donde las demandas diversas de los mapuche abrieron una arista en el debate en torno a la nueva constitución y su participación en ese proceso.

Para finalizar, destacamos que las temáticas abordadas dan cuenta del abanico de problemas abiertos que amalgaman la realidad latinoamericana actual. Desde una lectura pluridisicplinar, pero fundamentalmente engarzada en la historicidad, se han reconstruido debates actuales que involucran procesos sociales, políticos y económicos complejos. Todos los trabajos rearticulan la relación entre los procesos de acumulación capitalista de las últimas décadas del siglo XX, las posibilidades-limitadas o no- de resistencias al despojo y la explotación de colectivos profundamente afectados por ese proceso como las comunidades étnico-identitarias, lxs trabajadorxs, las mujeres y el feminismo, que a su vez se imbrican en dinámicas regionales diferenciadas.

Como reflexiones que se iniciaron en un tiempo pre pandemia, pero que fueron profundamente permeadas por ella en el devenir de su escritura, los artículos contenidos en este dossier renuevan el análisis sobre los problemas sociales actuales y, al igual que las palabras del Jano de Ovidio, nos congregan en los principios de este nuevo tiempo.

\section{Laura Luciani}

Centro Latinoamericano de Investigaciones en Historia Oral, Universidad Nacional de Rosario/Investigaciones Socio-históricas Regionales, Consejo Nacional de Investigaciones Cientificas y Técnicas (Argentina)

\section{Bibliografia}

Borón, A. (2012). América Latina en la geopolítica del imperialismo. Buenos Aires: Ediciones Luxemburg.

García Linera, A. (2017) ¿Fin de ciclo progresista o proceso por oleadas revolucionarias?. En Rebelión. Disponible online en: https://rebelion.org/finde-ciclo-progresista-o-proceso-por-oleadas-revolucionarias /

Modonessi, M. (2019). El progresismo latinoamericano: un debate de época. En Gaudichaud, F., J. Webber, M. Modonesi. Los gobiernos progresistas 
latinoamericanos del siglo XXI. Ensayos de interpretación histórica. México: UNAM Ediciones.

Machado, D. y Zibecchi, R. (2016) Cambiar el mundo desde arriba. Los límites del progresismo. México: Bajo Tierra A.C., Comunidad Autonomía y Libertad (Comunal).

Svampa, M. y E. Viale (2014). Maldesarrollo. La Argentina del extractivismo y el despojo. Buenos Aires: Katz Editores. 